\title{
Closing the loop in a constructed wetland for the improvement of metal removal: the use of Phragmites australis biomass harvested from the system as biosorbent
}

\author{
Elisabetta Bianchi ${ }^{1} \cdot$ Andrea Coppi $^{1} \cdot$ Simone Nucci $^{1}$ - Alexandra Antal ${ }^{2} \cdot$ Chiara Berardi $^{2}$ - Ester Coppini ${ }^{2}$. \\ Donatella Fibbi ${ }^{2} \cdot$ Massimo Del Bubba $^{3} \cdot$ Cristina Gonnelli $^{1} \cdot$ Ilaria Colzi ${ }^{1}$ (i)
}

Received: 15 June 2020 / Accepted: 18 October 2020 / Published online: 29 October 2020

(C) The Author(s) 2020

\begin{abstract}
Among the numerous clean-up techniques for water treatment, sorption methods are widely used for the removal of trace metals. Phragmites australis is a macrophyte commonly used in constructed wetlands for water purification, and in the last decades, its use as biosorbent has attracted increasing attention. In view of a circularly economy approach, this study investigated improvement of trace metal removal by recycling the biomass of $P$. australis colonizing a constructed wetland, which operates as posttreatment of effluent wastewater from an activated sludge plant serving the textile industrial district of Prato (Italy). After the annual mowing of the reed plants, the biomass was dried and blended to derive a sustainable and eco-friendly biosorbent and its sorption capacity for $\mathrm{Fe}, \mathrm{Cu}$, and $\mathrm{Zn}$ was investigated comparing the batch system with the easier-to-handle column technique. The possibility of regeneration and reuse of the biosorbent was also evaluated. The biomaterial showed an interesting sorption capacity for $\mathrm{Cu}, \mathrm{Fe}$, and $\mathrm{Zn}$, both in batch and in column experiments, especially for $\mathrm{Fe}$ ions. The immobilization of the biosorbent in column filters induced some improvement in the removal efficiency, and, in addition, this operation mode has the advantage of being much more suitable for practical applications than the batch process.
\end{abstract}

Keywords Biosorption $\cdot$ Circular economy $\cdot$ Columns $\cdot$ Trace metal removal $\cdot$ Plant dead biomass

\section{Introduction}

In this century, water pollution is of increasing concern to society, in addition exacerbated by the problem of water availability as a result of climate changes. Therefore, preventing the sources of water pollution further reaching the water bodies and cleaning the already polluted wastewaters are equally acquiring compulsory importance (Newete and Byrne 2016).

Trace metals represent the most common pollutants of high concern, since they cannot be biodegraded and can therefore

Responsible Editor: Alexandros Stefanakis

Ilaria Colzi

ilaria.colzi@unifi.it

1 Department of Biology, Università degli Studi di Firenze, via Micheli 1, 50121 Florence, Italy

2 GIDA S.p.A., via di Baciacavallo, 36, 59100 Prato, Italy

3 Department of Chemistry, Università degli Studi di Firenze, Via della Lastruccia 3, 50019 Sesto Fiorentino, Florence, Italy accumulate in waters and soils (Ali et al. 2013). Into aquatic bodies, metals are mainly released from anthropogenic sources, even though in particular environments, their natural origin can be significant (Schwarzenbach et al. 2006). Excessive levels of such elements can cause serious toxic effects at any level of the ecosystem, including several health problems (Ali et al. 2013; Rahman and Singh 2019).

Conventional physical and/or chemical methods for the treatment of wastewater are expensive and not eco-friendly (Sharma et al. 2014); therefore, in the last decades, several methodologies have been developed for cleaning water. Among them, constructed wetlands (CWs) are effective systems based on the use of macrophytes that exploit their high growth rate and large root apparatus for the direct uptake of pollutants (Fibbi et al. 2012; Mitsch 2012; Newete and Byrne 2016) and, above all, for the synergistic interactions with the microbial communities of CWs (Sacco et al. 2006; Truu et al. 2009). Such simple and low-cost technology is extensively used for the treatment of domestic sewage, as well as of industrial and agricultural wastewater (Gorgoglione and Torretta 2018; Masi et al. 2018). In fact, CWs can efficiently 
lower a wide range of pollutants, including metals that are removed thanks to precipitation and complexation mechanisms (Marchand et al. 2010), and to the considerable ability of macrophytes to accumulate such elements from water (Ali et al. 2013; Sharma et al. 2014).

Recently, another economic and eco-friendly alternative technology that is emerging for wastewater treatment is represented by the use of adsorbents derived from different biological materials, preferably low-cost wastes (Fu and Wang 2011; Srivastava et al. 2015; Del Bubba et al. 2020). A wide range of natural biomasses with sorptive properties has been tested for metal removal from contaminated water (e.g., Gupta et al. 2015). Among them, plant-derived materials are one of the favorite substrates, since they are renewable, abundant, easy to handle, cost-effective, and do not present many problems for their final disposal (Rai 2009; Ahluwalia and Goyal 2007; Srivastava et al. 2015). Biosorbents obtained from dried plant biomass, including those derived from agricultural waste products (Bhabhatnagar and Sillanpaa 2010; Castro et al. 2017; Petrovic et al. 2017), are the most frequently proposed for the removal of trace metals from wastewater (Guyo and Moyo 2017; Kamar et al. 2017; Saha et al. 2017; Sao et al. 2017, Colzi et al. 2018). Valid candidates, as non-living biomass sources, have been identified even in several macrophyte species (Bunluesin et al. 2007; Halaimi et al. 2014; Módenes et al. 2017; Rodrigues et al. 2017; Yi et al. 2017), and among them, the dried biomass of Phragmites australis (Cav.) Trin. ex Steudel. is attracting increasing attention. Actually, $P$. australis, a perennial helophyte grass generally found in tropical and temperate wetlands (Batty 2003), is the plant species most commonly employed in CWs for the wastewater treatment, able to enhance the removal of contaminants by adsorption, accumulation, and oxidation (Lee and Scholz 2007). Besides the active role of $P$. australis in CWs, also its non-living biomass has been reported to have a remarkable sorption capacity, coupled to easy desorption and regeneration by acid elution, for $\mathrm{Cu}, \mathrm{Cd}, \mathrm{Ni}, \mathrm{Pb}$, and $\mathrm{Zn}$, thanks to its high concentrations of lignin and cellulose (Southichak et al. 2006). Further batch experiments showed that also Hg was effectively bioremoved by $P$. australis dried biomass (Kankiliç et al. 2018), together with Cr, by the powder derived from $P$. australis roots (Akunwa et al. 2014). Moreover, considering the worldwide distribution of $P$. australis in nature and its use in CWs, where the management of mature plants is required, these appropriate features make $P$. australis dried biomass a good candidate as renewable biosorbent material.

In this study, we devised a strategy to exploit the biomass of $P$. australis harvested in a $\mathrm{CW}$ working as tertiary treatment of a membrane bioreactor wastewater treatment plant (WWTP) designed to pre-treat a mixture of landfill leachates prior to being conveyed in an activated sludge WWTP
(Coppini et al. 2019). Although $\mathrm{CW}$ is able to lower $\mathrm{Cu}, \mathrm{Fe}$, and $\mathrm{Zn}$ concentrations (Coppini et al. 2019), they still remain above the limits established by the Italian law for discharge into surface waters (Legislative Decree 152/06). Despite CW effluent is then further treated in the activate sludge WWTP and metals are removed, the use of harvested $\mathrm{CW}$ biomass is here proposed as an alternative way to optimize the $\mathrm{CW}$ treatment. More precisely, this study aims at exploiting the dried biomass of $P$. australis plants, coming from the annual mowing of the $\mathrm{CW}$, to derive a sustainable and eco-friendly biosorbent for the removal of the abovementioned elements from the $\mathrm{CW}$ effluent. The approach is in accordance with a circular economy model, since the biomaterial comes from the $\mathrm{CW}$, thus giving it a second life before its disposal as waste. The biosorbent derived from the $P$. australis dried biomass was tested for $\mathrm{Cu}, \mathrm{Fe}$, and $\mathrm{Zn}$ removal both in batch mode and in an easier-to-handle column system. Some papers in literature report for $P$. australis biomass successful trials in batch experiments (see references above); however, to the best of our knowledge, only one previous study used a column system to investigate the sorption ability of $P$. australis dried biomass for $\mathrm{Cr}(\mathrm{VI})$ removal (Lagiopoulos et al. 2017). Therefore, this is the first report that investigates the possible use of $P$. australis dried biomass recycled from a $\mathrm{CW}$ for the generation of a column system to optimize the removal of $\mathrm{Cu}$, $\mathrm{Fe}$, and $\mathrm{Zn}$. The results will be of fundamental importance to suggest an easy, effective, and "green" strategy that any CWbased treatment plant could experience for the cleaning of the most precious resource of the earth, water.

\section{Materials and methods}

\section{Biomass and synthetic wastewater preparation}

Phragmites australis plants were collected from the $\mathrm{CW}$ at the Calice WWTP (Prato, Italy) for urban and industrial wastewater treatment, managed by the company Gestione Impianti Depurazione Acque (GIDA S.p.A.). In the lab, plant shoots were cut, cleaned with distillated water, and dried at $60{ }^{\circ} \mathrm{C}$ in an oven. Once dried, the plant biomass was ground by an electric grinder and sieved to $0.5 \mathrm{~mm}$ to obtain a homogeneous powder.

For the experiment, a synthetic wastewater (SWW) with $\mathrm{pH}$ and metal concentration similar to the real influent of the Calice WWTP (data provided by GIDA S.p.A.) was prepared. The necessary amount of metal salts $\left(\mathrm{Cu}\left(\mathrm{NO}_{3}\right)_{2} \cdot 5 \mathrm{H}_{2} \mathrm{O}\right.$, $\mathrm{FeSO}_{4} \cdot 7 \mathrm{H}_{2} \mathrm{O}$, and $\left.\mathrm{Zn}\left(\mathrm{NO}_{3}\right)_{2} \cdot 6 \mathrm{H}_{2} \mathrm{O}\right)$ was dissolved in deionized water to obtain the corresponding metal ion concentration in the synthetic water: $\mathrm{Cu}$ (II) $0.3 \mathrm{mg} \mathrm{L}^{-1}, \mathrm{Fe}$ (II) $8 \mathrm{mg} \mathrm{L}^{-1}$, and $\mathrm{Zn}$ (II) $2 \mathrm{mg} \mathrm{L}^{-1}$. The $\mathrm{pH}$ of the solution was adjusted with $\mathrm{NH}_{4} \mathrm{OH}$ to simulate the value of the real wastewater influent of the Calice WWTP $(7.8 \pm 0.2)$. 


\section{Batch experiment}

Batch experiments were performed using 250-mL conical flasks (9 replicates) containing $100 \mathrm{~mL}$ of SWW and about $8.7 \mathrm{~g}$ of $P$. australis dried biomass. The biosorbent was allowed to come into contact with the solution for $20 \mathrm{~min}$ on a magnetic stirrer. Subsequently, the solution was filtered through $0.45-\mu \mathrm{m}$ filter paper, and the metal concentrations were determined as described below, both in the supernatant and in the biosorbent.

\section{Column filtration experiment}

The column filtration system was realized at the lab scale (Fig. 1), and was composed of a plexiglass cylinder (height $25 \mathrm{~cm}$, internal diameter $7.6 \mathrm{~cm}$ ) completely filled with dried $P$. australis biomass (about $175 \mathrm{~g}$ for each column). Perforated caps with disks of filter paper $(0.45 \mu \mathrm{m})$ were placed at the top and at the bottom of the column, to enable a uniform distribution of the inlet and outlet flow of wastewater and to support the biosorbent, preventing any loss. For convenience, the column was inserted into a support cylinder with a larger diameter (Plexiglas, height $65 \mathrm{~cm}$, internal diameter $8.2 \mathrm{~cm}$ ). The column was equipped with a graduated Plexiglas reservoir, which was placed above the top filter. The column experiments were performed by adding $2 \mathrm{~L}$ of SWW to the tank and letting it percolate through the $P$. australis biosorbent filter. After the filtration, about $2 \mathrm{~g}$ of fresh weight (f.w.) P. australis biomass (corresponding to $0.5 \mathrm{~g}$ of dry weight (d.w.)) and SWW (90 mL) aliquots were collected and used for the determination of metal concentrations. The filtration through the biosorbent was repeated 4 times (F1-F4), adding $2 \mathrm{~L}$ of new SWW every time, for a total of $8 \mathrm{~L}$ of filtered liquid through each column. Prior to each filtration with the SWW, the columns were washed with $2 \mathrm{~L}$ of deionized water in order to check the absence of element release from the plant biomass to the liquid. Moreover, aliquots of plant biomass and SWW before the beginning of the filtration experiments were sampled and used for the determination of metal concentration at the beginning of the experiment $\left(t_{0}\right)$.

The experiments were conducted at room temperature $(25$ $\pm 2{ }^{\circ} \mathrm{C}$ ), and the percolation rate was $100 \mathrm{~mL}$ per min.

\section{Desorption and reuse of the biosorbent}

A desorption experiment was conducted by passing $1 \mathrm{~L}$ of $0.1 \mathrm{M} \mathrm{HCl}$ (regeneration solution) directly through the columns containing the $P$. australis biosorbent. Afterwards, $2 \mathrm{~L}$ of deionized water was let to percolate through the column to remove any trace of acid. Aliquots of the regeneration solution $(90 \mathrm{~mL})$ and biosorbent $(0.5 \mathrm{~g}$ d.w. $)$ were collected after each leaching and used for the determination of metal concentrations. The whole desorption procedure was repeated three times (D1-D3), adding $1 \mathrm{~L}$ of new regeneration solution every time, for a total of $3 \mathrm{~L}$ of diluted $\mathrm{HCl}$ used for each column system.

At the end of the desorption procedure, the reusability of the biosorbent was tested by carrying out a new percolation experiment. Two consecutive filtrations, using new SWW every time, were performed, following the same procedure described in "Desorption and reuse of the biosorbent" section.

\section{Determination of metal concentrations}

The concentrations of $\mathrm{Cu}, \mathrm{Fe}$, and $\mathrm{Zn}$ in $P$. australis biosorbent and liquid samples (SWW and regeneration solution) were determined through mineralization in a microwave

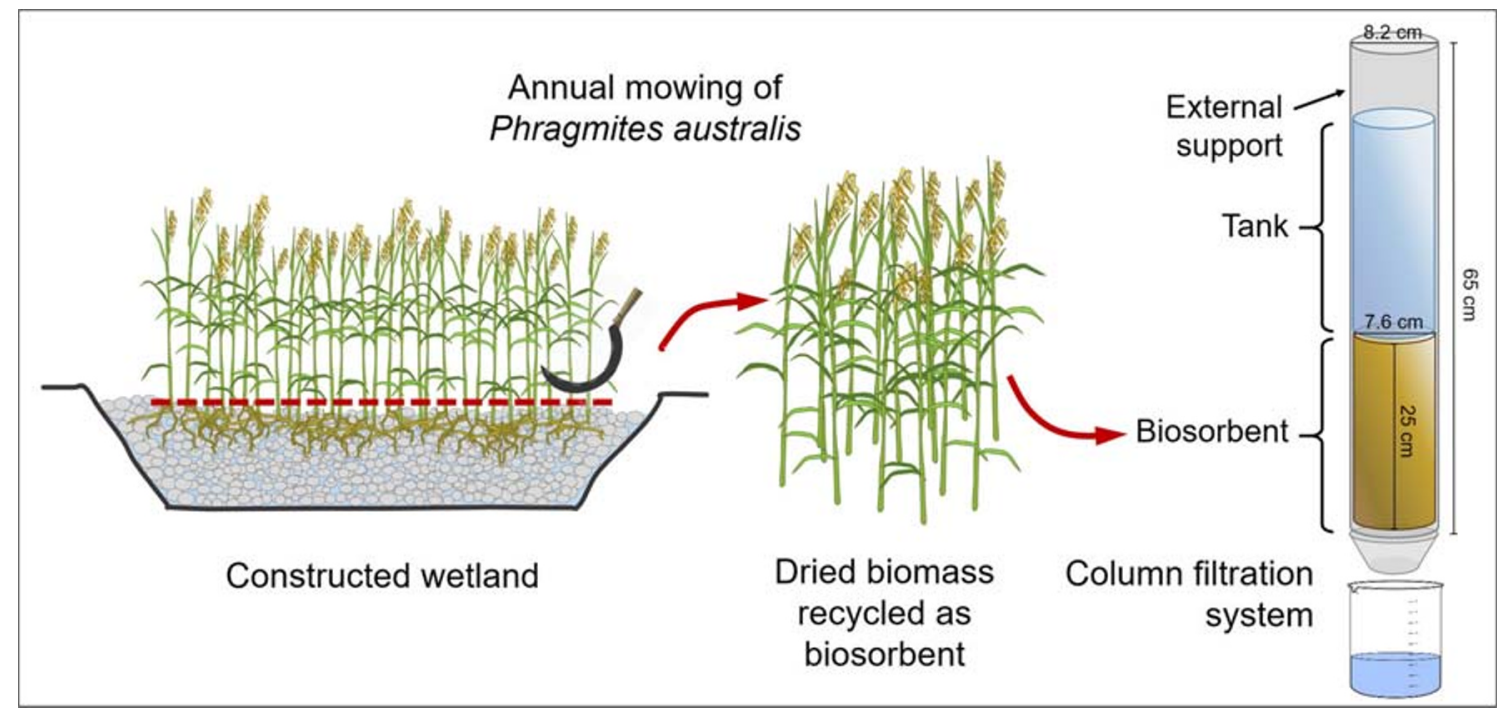

Fig. 1 Experimental setup for column filtration studies 
digestion system (Mars 6, CEM) and subsequent analysis by atomic absorption spectrometry (PinAAcle 500, Perkin Elmer). In particular, the plant biomass was blotted dry on paper to remove any residue of SWW and then dried in the oven at $60{ }^{\circ} \mathrm{C}$ for at least $24 \mathrm{~h}$. About $0.1 \mathrm{~g}$ d.w. of material was digested using $10 \mathrm{~mL}$ of $\mathrm{HNO}_{3} 69 \%$ (according to Bettarini et al. 2019), and at the end of mineralization, the volume was adjusted to $25 \mathrm{~mL}$ with Milli-Q water (Millipore, Burlington, MA, USA).

All the liquid samples were filtered through a $0.45-\mu \mathrm{m}$ filter paper, in order to separate possible suspended material that could influence the metal measurements. Aliquots of 20 $\mathrm{mL}$ were used for the digestion by adding $1.5 \mathrm{~mL}$ of $\mathrm{HNO}_{3}$ $69 \%$ and $1 \mathrm{~mL}$ of $\mathrm{HCl} 37 \%$ (according to US EPA3015a), and the final volume was adjusted to $25 \mathrm{~mL}$ with Milli-Q water.

The percentage of metal removal by $P$. australis biomass was calculated based on the decrease of element concentrations in the SWW $\left(R \%_{\mathrm{SWW}}\right)$ after batch/column experiments, according to Eq. (1):

$\mathrm{R} \%_{\mathrm{SWW}}=\frac{\mathrm{C}_{\mathrm{SWW}}^{\mathrm{t}_{0}}-\mathrm{C}_{\mathrm{SWW}}^{\mathrm{t}_{\text {end }}}}{\mathrm{C}_{\mathrm{SWW}}^{\mathrm{t}_{0}}} \times 100$

where

$C_{\mathrm{SWW}}^{t_{0}}$ metal concentration $\left(\mathrm{mg} \mathrm{L}^{-1}\right)$ in the SWW at $t_{0}$ (before batch/column experiments)

$C_{\mathrm{SWW}}^{\mathrm{t} \text { end }} \quad$ metal concentration $\left(\mathrm{mg} \mathrm{L}^{-1}\right)$ in the SWW after batch experiment and each one of the percolation/ desorption cycles.

Moreover, the removal percentage of metals was calculated as reported in Colzi et al. (2018), based on the concentration found in the $P$. australis biomass ( $R \%_{\text {biomass }}$ ) after batch/ column experiment, according to Eq. (2):

$\mathrm{R} \%_{\text {biomass }}=\frac{\mathrm{M}_{\text {biomass }}^{\mathrm{t}_{\mathrm{n}+1}}-\mathrm{M}_{\text {biomass }}^{\mathrm{t}_{\mathrm{n}}}}{\mathrm{C}_{\mathrm{SWW}}^{\mathrm{t}_{\mathrm{O}}} \times \mathrm{V}} \times 100$

where

$M_{\text {biomass }}^{t_{n}} \quad$ metal amount ( $\left.\mu \mathrm{g}\right)$ in the biosorbent before (i) the batch experiment or (ii) each one of the percolation/desorption cycles.

$M_{\text {biomass }}^{t_{n+1}} \quad$ metal amount ( $\left.\mu \mathrm{g}\right)$ in the biosorbent after (i) the batch experiment or (ii) each one of the column percolation/desorption cycles.

$C_{\mathrm{SWW}}^{t_{0}}$ metal concentration $\left(\mu \mathrm{g} \mathrm{L}^{-1}\right)$ in the SWW at $t_{0}$ (before batch/column experiments)

$V \quad$ volume of the SWW (L) used for the batch experiment and each column percolation/desorption cycles.

\section{Statistics}

Plot drawing and statistical analysis were conducted using GraphPad Prism 8 for Windows. One-way ANOVA was performed to compare mean values, and Tukey post hoc test was used for a posteriori comparison of individual means (with at least $p<0.05$ as significance level).

\section{Results and discussion}

\section{Batch experiment}

The batch experiment was performed allowing the $P$. australis biomass to come into contact with the SWW for $20 \mathrm{~min}$. Since a rapid sorption is important for improving the process efficiency in practical application, we purposely decided to test the biosorption capacity of the $P$. australis biosorbent only at a short contact time. Rapid metal biosorption in batch tests has been reported for several kinds of biomass, reaching the kinetic equilibrium within 20 min (e.g., Keskinkan et al. 2004; Bunluesin et al. 2007; Kariuki et al. 2017; Abdić et al. 2018).

Metal concentrations $(\mathrm{Cu}, \mathrm{Fe}$, and $\mathrm{Zn})$ in $\mathrm{SWW}$ and $P$. australis biomass determined before and after the batch sorption are reported in Table 1. In the synthetic solution, all metal concentrations significantly decreased after the batch experiment, and corresponding concentration increases were observed in the $P$. australis biomass. The plant biomass showed an efficient sorption capacity, reaching the highest percentage of removal determined in the SWW ( $R \%_{\text {Sww }}$, Eq. (1)) for $\mathrm{Fe}$ (about 95\%), followed by $\mathrm{Zn}$ (about 73\%)

Table 1 Metal concentration (mean of 9 replicates \pm SD) in the synthetic wastewater (SWW, $\mathrm{mg} \mathrm{L}^{-1}$ ) and in the $P$. australis biomass $\left(\mu \mathrm{g} \mathrm{g}^{-1}\right.$ d.w.) and percentages of metal removal (\%) after the batch sorption for $20 \mathrm{~min}$

Metals

\begin{tabular}{|c|c|c|c|c|c|c|c|c|}
\hline & $\mathrm{Cu}$ & & & $\mathrm{Fe}$ & & $\mathrm{Zn}$ & & \\
\hline \multicolumn{9}{|l|}{ SWW (mg L $\left.{ }^{-1}\right)$} \\
\hline Before sorption & 0.30 & \pm & $0.01 \mathrm{a}$ & 8.1 & $\pm 0.5 \mathrm{a}$ & 2.12 & \pm & $0.08 \mathrm{a}$ \\
\hline After sorption & 0.11 & \pm & $0.01 \mathrm{~b}$ & 0.6 & $\pm 0.1 \mathrm{~b}$ & 0.53 & \pm & $0.03 b$ \\
\hline \multicolumn{9}{|c|}{ Biomass ( $\mu \mathrm{g} \mathrm{g}^{-1}$ d.w.) } \\
\hline Before sorption & 2.2 & \pm & $0.3 b$ & 39 & $\pm 5 b$ & 32 & \pm & $4 \mathrm{~b}$ \\
\hline After sorption & 4.3 & \pm & $0.3 \mathrm{a}$ & 126 & $\pm 4 a$ & 49 & \pm & $2 \mathrm{a}$ \\
\hline \multicolumn{9}{|l|}{ Removal (\%) } \\
\hline$R \%_{\mathrm{SWW}}$ & 61 & $\pm 3 \mathrm{c}$ & $3 \mathrm{c}$ & 93 & $\pm 1 \mathrm{a}$ & 73 & \pm & $1 \mathrm{~b}$ \\
\hline$R \%_{\text {biomass }}$ & 60 & $\pm 5 \mathrm{c}$ & $5 \mathrm{c}$ & 95 & $\pm 4 \mathrm{a}$ & 73 & \pm & $4 \mathrm{~b}$ \\
\hline
\end{tabular}

Significant differences before and after the sorption appear with different letters (at least $p<0.05$ ) 
and $\mathrm{Cu}$ (about $61 \%$ ). The removals calculated on the basis of the concentrations determined in the plant biomass ( $R \%_{\text {biomass }}$, Eq. (2)) were in agreement with $R \%_{\text {sww }}$ data and confirmed the same trend. A similar metal biosorption capacity of $P$. australis biomass was already observed in the case of $\mathrm{Hg}$, reaching about $75 \%$ of removal within $20 \mathrm{~min}$ (Kankiliç et al. 2018). Rapid and efficient metal biosorption has been reported also for other macrophyte-based biomaterials. For instance, Bunluesin et al. (2007) reported an $80 \%$ biosorption efficiency of Hydrilla verticillata biomass during the first 3-5 min of batch sorption for $\mathrm{Cd}$ removal, reaching the equilibrium within $20 \mathrm{~min}$ of contact time, similarly to the case of $\mathrm{Zn}, \mathrm{Pb}$, and $\mathrm{Cu}$ sorption by Ceratophyllum demersum (Keskinkan et al. 2004), and $\mathrm{Cu}, \mathrm{Pb}$, and $\mathrm{Cr}$ by Sagittaria trifolia (Zhang et al. 2018). Residual Fe concentration in the SWW $\left(0.6 \mathrm{mg} \mathrm{L}^{-1}\right)$ was much below the limits for wastewater discharge in surface waters $\left(2 \mathrm{mg} \mathrm{L}^{-1}\right)$ indicated by Italian law (Legislative Decree 152/06), whereas $\mathrm{Cu}$ and Zn SWW concentrations after the batch sorption experiment $(0.11$ and $0.53 \mathrm{mg} \mathrm{L}^{-1}$ ) were around the corresponding threshold values (0.1 $\mathrm{mg} \mathrm{L}^{-1}$ for $\mathrm{Cu}$ and $0.5 \mathrm{mg} \mathrm{L}^{-1}$ for $\mathrm{Zn}$ ).

\section{Column filtration experiment}

Since the dead biomass of $P$. australis showed a remarkable sorption capacity for the studied elements in short-term batch experiment, in view of a greater optimization of metal removal for practical application, a column filtration system was tested. Usually, thinking about an upgrading of the process at a larger scale, column systems are considered preferable for a continuous wastewater treatment. Moreover, they allow a more efficient and economical utilization of the biosorbents than a batch mode, avoiding all the necessary operations for separating the biomass from the liquid after treatment (Vinodhini and Das 2010). In addition, our column system was conceived for a smart handling, since the removable filtration cylinder

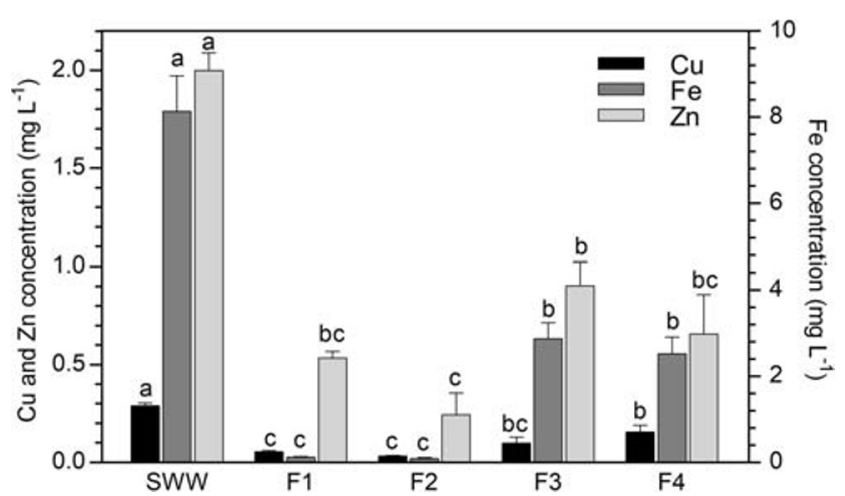

Fig. 2 Metal concentration $\left(\mathrm{mg} \mathrm{L}^{-1}\right)$ in the synthetic water before (SWW) and after the percolation (F1-F4) through the column system (mean of 15 replicates \pm SE). Significant differences among the filtrations appear with different letters (at least $p<0.05$ ) containing the biosorbent dovetails with the external support column and can be easily extracted and replaced when saturated.

As illustrated in Fig. 2, the filtration of SWW through the biosorbent resulted in a statistically significant decrease in the concentrations of all metals in the column effluent, compared with the influent solution. Such significant reduction of the metal concentrations was observed for after all the 4 performed filtrations. Therefore, the column system showed a high efficiency in reducing the metal concentrations from the SWW, reaching the best performances in F1 and F2, these latter percolation cycles being the ones that provided the lowest metal concentrations in the column outlet. An increasing trend of the column effluent concentrations was then observed (i.e., in F3 and F4), evidencing a tendency to saturation of the biosorbent. With increasing the volume of treated SWW the sorption efficiency was lower, however the column system could be used with a pre-treatment purpose, followed by a subsequent additional depuration through the $\mathrm{CW}$ plant.

In the $P$. australis biomass (Fig. 3), the concentration of all the metals increased with increasing the number of consecutive filtrations, even though the amount of elements retained by the column after each filtration tended to decrease from F1 to F4. Obviously, the initial higher sorption capacity is due to the abundance of free binding sites, which decrease during the filtration process.

The removals calculated on the basis of the concentrations determined in the SWW ( $R \%_{\mathrm{SWW}}$, Eq. (1)) or in the biomass $\left(R \%_{\text {biomass }}\right.$, Eq. (2)) were found to be in agreement with each other. These values were in the ranges of about $46-80 \%, 70$ $100 \%$, and $65-85 \%$ for $\mathrm{Cu}, \mathrm{Fe}$, and $\mathrm{Zn}$, respectively (Table 2 ). Considering that for the first percolation cycle of the column experiment the ratio between the biomass weight and the SWW volume was the same of the batch study (i.e., $87 \mathrm{~g}$ $\left.\mathrm{L}^{-1}\right)$, it is possible to compare the two treatment approaches, evidencing removal percentages similar (for $\mathrm{Fe}$ and $\mathrm{Zn}$ ) or higher (for $\mathrm{Cu}$ ) than those obtained in the batch study.

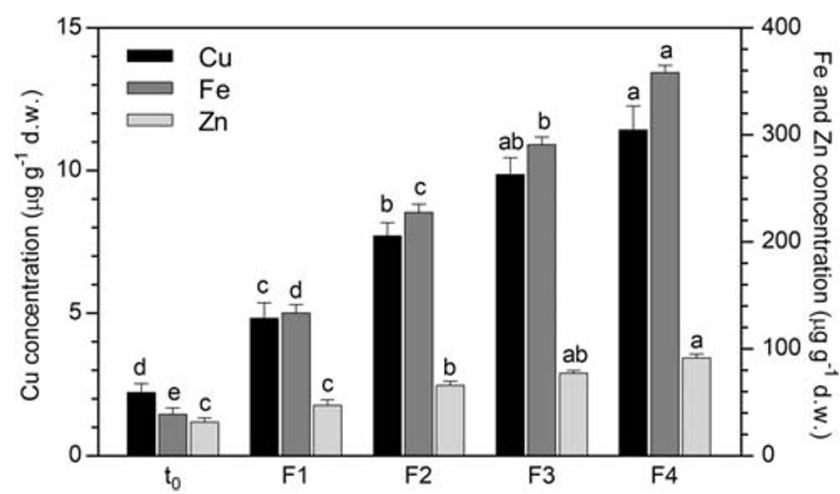

Fig. 3 Metal concentration $\left(\mu \mathrm{g} \mathrm{g}^{-1}\right)$ in the $P$. australis biomass before $\left(t_{0}\right)$ and after the percolation (F1-F4) of SWW through the column system (mean of 15 replicates $\pm \mathrm{SE}$ ). Significant differences among the filtrations appear with different letters (at least $p<0.05$ ) 
Table 2 Percentages of metal removal of $P$. australis biomass (mean of 15 replicates \pm SD) after each filtration through the column system

\begin{tabular}{|c|c|c|c|c|c|c|c|c|c|}
\hline \multicolumn{10}{|c|}{ Metals } \\
\hline & \multicolumn{3}{|l|}{$\mathrm{Cu}$} & \multicolumn{3}{|l|}{$\mathrm{Fe}$} & \multicolumn{3}{|l|}{$\mathrm{Zn}$} \\
\hline \multicolumn{10}{|c|}{$R \%_{\mathrm{SWW}}$} \\
\hline $\mathrm{F} 1$ & 81 & \pm & $2 \mathrm{aB}$ & 98 & \pm & $2 \mathrm{aA}$ & 72 & \pm & $2 \mathrm{bC}$ \\
\hline $\mathrm{F} 2$ & 89 & \pm & $1 \mathrm{bB}$ & 99 & \pm & $2 \mathrm{aA}$ & 87 & \pm & $5 \mathrm{aB}$ \\
\hline F3 & 66 & \pm & $9 \mathrm{cdA}$ & 64 & \pm & $4 \mathrm{bA}$ & 52 & \pm & $6 \mathrm{cA}$ \\
\hline F4 & 46 & \pm & $5 \mathrm{~dB}$ & 69 & \pm & $4 \mathrm{bA}$ & 65 & \pm & $9 \mathrm{bcAB}$ \\
\hline \multicolumn{10}{|c|}{$R \%_{\text {biomass }}$} \\
\hline $\mathrm{F} 1$ & 79 & \pm & $6 \mathrm{aB}$ & 102 & \pm & $8 \mathrm{aA}$ & 72 & \pm & $2 \mathrm{aB}$ \\
\hline $\mathrm{F} 2$ & 86 & \pm & $5 \mathrm{aB}$ & 101 & \pm & $4 \mathrm{aA}$ & 86 & \pm & $8 \mathrm{aB}$ \\
\hline F3 & 65 & \pm & $7 \mathrm{bB}$ & 68 & \pm & $3 \mathrm{aA}$ & 52 & \pm & $4 \mathrm{aB}$ \\
\hline F4 & 46 & \pm & $9 \mathrm{cB}$ & 72 & \pm & $2 \mathrm{aA}$ & 65 & \pm & $4 \mathrm{aB}$ \\
\hline
\end{tabular}

Significant differences appear with different letters, small for the comparison among the filtrations and capital for the comparison among the metals (at least $p<0.05$ )

As for the comparison with previously published biosorption data, most of the biomaterials reported in literature for metal removal with column systems are based on agricultural wastes recycled from the food production chain (e.g., Pérez Marín et al. 2009; Iqbal et al. 2013; Chao et al. 2014; Abdolali et al. 2017; Dong and Lin 2017). A fewer number of studies took into consideration plant biomass (Karunasagar et al. 2005; Stanovych et al. 2019), and, to the best of our knowledge, only one paper tested $P$. australis dried biomass in column mode for the removal of $\mathrm{Cr}(\mathrm{VI})$ (Lagiopoulos et al. 2017). The comparison of the results obtained here with those previously reported in the literature is complicated by the fact that the metal removal efficiencies, in addition to the type of biosorbent (often chemically modified prior its use as biosorbent), are strongly affected by a number of operating parameters such as the percolation rate and the metal concentration of the influent solution (Abdolali et al. 2017). In this study, the concentrations of metals accumulated in the biomaterial resulted quite lower than the corresponding values determined elsewhere (Vijayaraghavan et al. 2005; Muhamad et al. 2010; Hasfalina et al. 2012; Acheampong et al. 2013; Chao et al. 2014; Martín-Lara et al. 2016; Talebian et al. 2016; Abdolali et al. 2017; Dong and Lin 2017; Tariq et al. 2019). In particular, the highest values reported in the literature were obtained with low percolation rates (a few $\mathrm{mL} \mathrm{min}^{-1}$ ) and high metal concentrations in the influent solution (from tens to hundreds of $\mathrm{mg} \mathrm{L}^{-1}$ ). However, it is evident that these experimental conditions are very far from those that should be achieved in a WWTP, where the concentrations of metal to be treated are normally lower and the water flow rates on the other hand much higher. Moreover, in our tests, the columns were not saturated, whereas literature data commonly refer to maximum sorptions obtained under breakthrough conditions.
Furthermore, the biomaterial used did not received a chemical pretreatment to improve its sorption potential in order to limit costs and the impact on the environment. It should also be noted that in some breakthrough studies performed in column packed with biosorbents, metal sorption is surprisingly reported to be far greater than the quantities of metal applied to the column itself (e.g., Acheampong et al. 2013; Abdolali et al. 2017).

\section{Desorption and reuse of the biosorbent}

The regeneration of the metal-loaded $P$. australis biosorbent and the possibility to reuse the column system prior to discharge the biomass is a very important aspect in view of a more sustainable and cost-effectiveness process. Moreover, the possible non-destructive recovery of the metal by desorbing agents would give to the process an added economic value (Vijayaraghavan and Yun 2008).

The column regeneration was performed with diluted $\mathrm{HCl}$ solution (regeneration solution), and the metal concentration was determined after the percolation through the $P$. australis biosorbent (Fig. 4). In general, a gradual decrease in the metal concentrations was observed with increasing the number of desorption leaching. The highest values were found after the first desorption (D1). After the second percolation with new regeneration solution (D2), the $\mathrm{Cu}$ concentration in the eluate was the same than after D1, whereas Fe and $\mathrm{Zn}$ concentrations were significantly lower. Finally, in the regeneration solution used for the third desorption (D3), the lowest metal concentrations were found, with the exception of $\mathrm{Fe}$, which did not show any significant decrease in comparison with D2.

In Fig. 5, the metal concentrations in P. australis biosorbent after three desorption filtrations with the regeneration solution are reported. Moreover, the figure shows the initial metal concentration in the $P$. australis biomass $\left(P_{t 0}\right)$ and the saturated level, reached after 4 consecutive filtrations of SWW $\left(P_{\mathrm{F} 4}\right)$. Starting from the metal saturated biomass

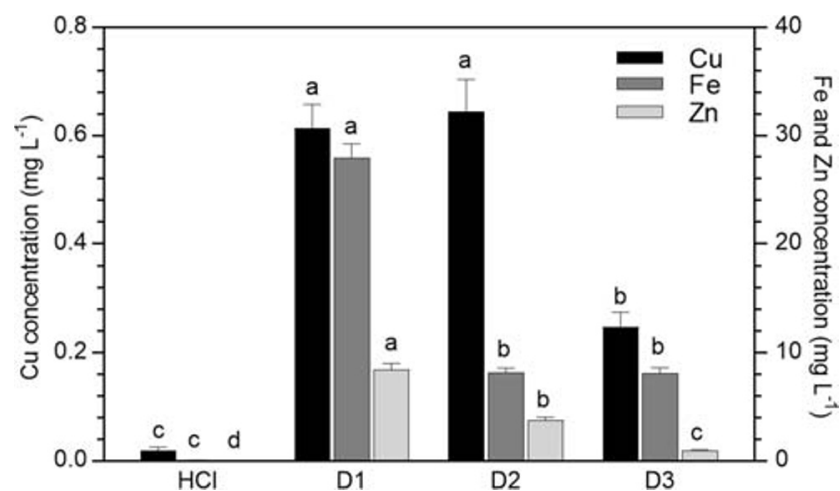

Fig. 4 Metal concentration $\left(\mathrm{mg} \mathrm{L}^{-1}\right)$ in the $\mathrm{HCl}$ solution before $(\mathrm{HCl})$ and after the percolation (D1-D3) through the column system (mean of 15 replicates $\pm \mathrm{SE}$ ). Significant differences among the desorption cycles appear with different letters (at least $p<0.05$ ) 


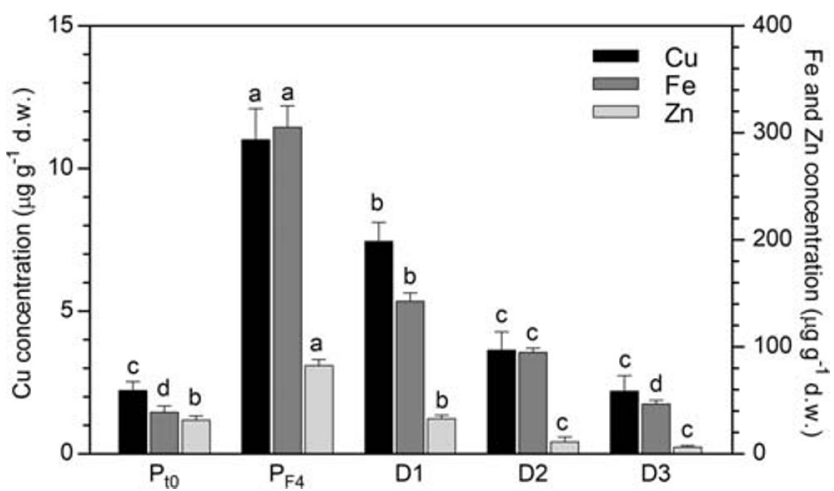

Fig. 5 Metal concentration $\left(\mu \mathrm{g} \mathrm{g}^{-1}\right)$ in the $P$. australis biosorbent after the desorption (D1-D3) with $\mathrm{HCl}$ (mean of 15 replicates $\pm \mathrm{SE}$ ). The metal concentration in the $P$. australis biomass before $\left(P_{t 0}\right)$ and after 4 consecutive filtrations of SWW $\left(P_{\mathrm{F} 4}\right)$ is also reported in the graph. Significant differences among $P_{t 0}, P_{\mathrm{F} 4}$, and the desorption filtrations appear with different letters (at least $p<0.05$ )

$\left(P_{\mathrm{F} 4}\right)$, a progressive significant decrease of the metal concentrations in the biosorbent was found with the increase in the number of desorption filtrations. In the case of $\mathrm{Fe}$, the biomass resulted completely desorbed after three filtrations with the regeneration solution, since the concentrations determined in the biosorbent were not significantly different from the initial values within the $P$. australis biomass $\left(P_{t 0}\right)$. As for $\mathrm{Cu}$ and $\mathrm{Zn}$, the same result was observed already after two (D2) and one desorption with the regeneration solution (D1), respectively.

The reusability of regenerated biosorbent was tested by performing new filtrations with SWW through the column system. As shown in Fig. 6, the regenerated biomass was still able to remove metal ions, since the residual concentrations in SWW after each filtrations (F1 and F2) were significantly decreased. In particular, for all the metals, the lowest values were found after the first filtration (F1), whereas after the second one (F2), the removal capacity was lower. Considering the Italian law, the concentrations determined in SWW after filtration were similar to the permitted emission limit values (Legislative Decree 152/06) only in the case of $\mathrm{Cu}$

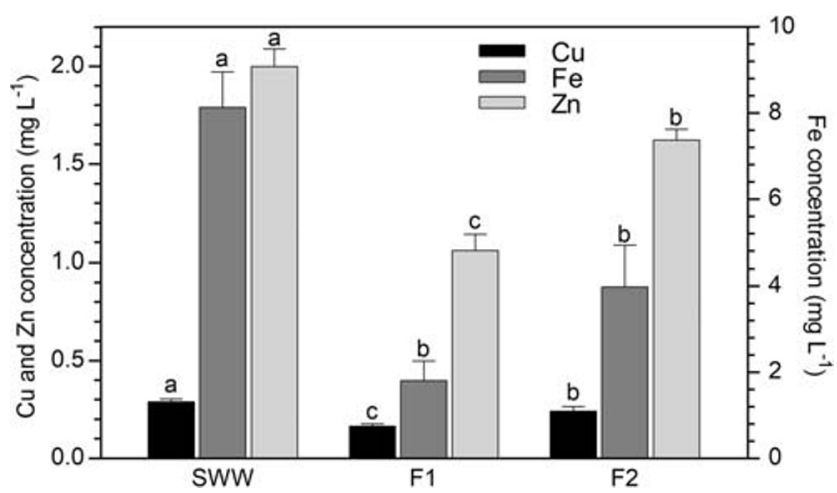

Fig. 6 Metal concentration $\left(\mathrm{mg} \mathrm{L}^{-1}\right)$ in the synthetic water before (SWW) and after the percolation (F1 and F2) through the regenerated column system (mean of 15 replicates \pm SE). Significant differences among the filtrations appear with different letters (at least $p<0.05$ ) and $\mathrm{Fe}$ after $\mathrm{F} 1$. In all the other cases, the values resulted above such threshold limits. However, such result would represent a small issue if the outlet of the column system is then destined to further treatments (e.g., through $\mathrm{CW}$ ).

Considering the metal concentrations in biosorbent after new filtrations (Fig. 7), starting from the regenerated biomass $\left(P_{\mathrm{D} 3}\right)$, in all cases, the values significantly increased both after F1 and after F2. Nonetheless, the concentrations obtained were always significantly lower than the ones reached in the first experiment after F1 and F2, and well far from the values reached after 4 consecutive filtrations $\left(P_{\mathrm{F} 4}\right)$. Such decrease in the sorption capacity after the regeneration is even more evident looking at the percentages of removal (Table 3), which were always significantly lower in respect to the ones found in the first use of the biosorbent. Therefore, despite the regenerated biosorbent proved to have still sorption capacity, the removal efficiency was decreased, probably due to possible biosorbent damage during desorption process, as already reported in literature for consecutive sorption-desorption cycles in column systems (Areco et al. 2012; Abdolali et al. 2017).

\section{Conclusions}

A renewable biosorbent based on Phragmites australis dried biomass is here proposed to optimize the performance of a $\mathrm{CW}$ for the treatment of landfill leachates. Following the circular economy approach, the $P$. australis biomass was recycled from the annual mowing of the $\mathrm{CW}$, combining the advantages of the improvement of wastewater remediation with an innovative way to manage and recycle the harvested plants, usually considered a waste.

The biomaterial showed an interesting sorption capacity for $\mathrm{Cu}, \mathrm{Fe}$, and $\mathrm{Zn}$, both in batch and in column mode, especially for Fe ions. The immobilization of the biosorbent in column

Table 3 Percentages of metal removal of $P$. australis regenerated biomass (mean of 15 replicates $\pm \mathrm{SE}$ ) after each filtration (F1 and F2) through the column system

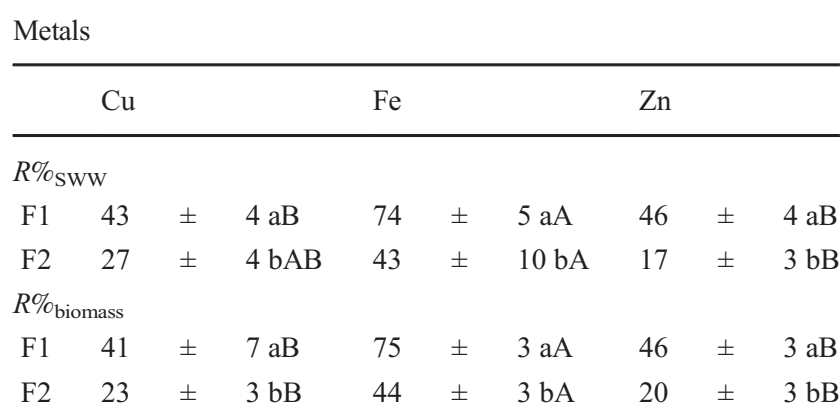

Significant differences appear with different letters, small for the comparison among the filtrations and capital for the comparison among the metals (at least $p<0.05$ ) 


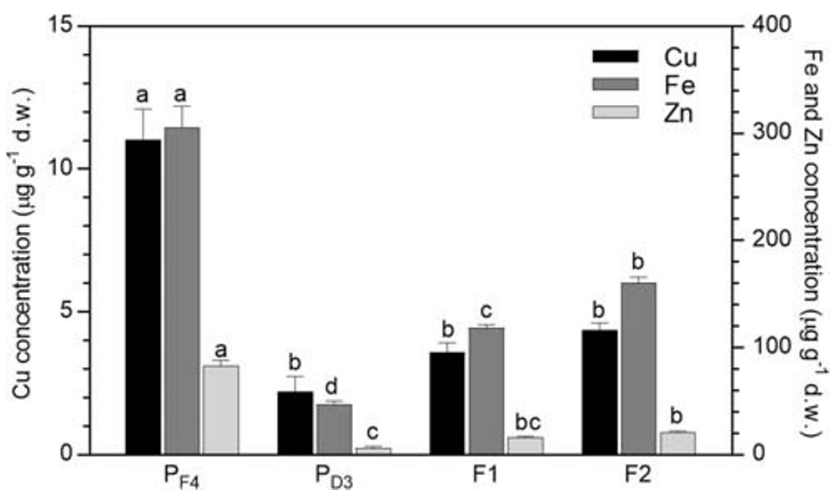

Fig. 7 Metal concentration $\left(\mu \mathrm{g} \mathrm{g}^{-1}\right)$ in the regenerated $P$. australis biosorbent after two new percolations (F1 and F2) of SWW through the column system (mean of 15 replicates $\pm \mathrm{SE}$ ). The metal concentration in the $P$. australis biomass before $\left(P_{\mathrm{F} 4}\right)$ and after regeneration with $\mathrm{HCl}$ $\left(P_{\mathrm{D} 3}\right)$ is also reported in the graph. Significant differences among $P_{\mathrm{F} 4}$, $P_{\mathrm{D} 3}$, and the filtrations appear with different letters (at least $p<0.05$ )

filters induced some improvement in the removal efficiency, and, in addition, this operation mode has the advantage of being much more suitable for practical applications than a batch process. Therefore, our sustainable column system filled with recycled $P$. australis biomass without any chemical modification showed a good potential in the metal removal from synthetic wastewater. Further studies are necessary to improve the reusability of the biosorbent and to optimize the technology using real wastewater.

Author contributions Conceptualization: EB, AC, CG, and IC. Data curation: EB and SN. Formal analysis: $\mathrm{EB}$ and IC. Investigation: EB and SN. Resources: AA, CB, EC, and DF. Supervision: AC, CG, and IC. Writing - original draft: $\mathrm{EB}, \mathrm{MB}, \mathrm{CG}$, and IC. Writing - review \& editing: $\mathrm{EB}, \mathrm{MB}, \mathrm{CG}$, and IC.

Funding Open access funding provided by Università degli Studi di Firenze within the CRUI-CARE Agreement. This work was funded by GIDA S.p.A. and by University of Florence (Fondi di Ateneo).

Data availability Data subject to third party restrictions.

\section{Compliance with ethical standards}

Ethics approval and consent to participate Not applicable.

\section{Consent for publication Not applicable.}

Competing interests The authors declare that they have no competing interests.

Open Access This article is licensed under a Creative Commons Attribution 4.0 International License, which permits use, sharing, adaptation, distribution and reproduction in any medium or format, as long as you give appropriate credit to the original author(s) and the source, provide a link to the Creative Commons licence, and indicate if changes were made. The images or other third party material in this article are included in the article's Creative Commons licence, unless indicated otherwise in a credit line to the material. If material is not included in the article's Creative Commons licence and your intended use is not permitted by statutory regulation or exceeds the permitted use, you will need to obtain permission directly from the copyright holder. To view a copy of this licence, visit http://creativecommons.org/licenses/by/4.0/.

\section{References}

Abdolali A, Ngo HH, Guo W, Zhou JL, Zhang J, Liang S, Chang SW, Nguyen DD, Liu Y (2017) Application of a breakthrough biosorbent for removing heavy metals from synthetic and real wastewaters in a lab-scale continuous fixed-bed column. Bioresour Technol 229:7887

Acheampong MA, Pakshirajan K, Annachhatre AP, Lens PNL (2013) Removal of $\mathrm{Cu}(\mathrm{II})$ by biosorption onto coconut shell in fixed-bed column systems. J Ind Eng Chem 19:841-848

Ahluwalia SS, Goyal D (2007) Microbial and plant derived biomass for removal of heavy metals from wastewater. Bioresour Technol 98: 2243-2257

Akunwa NK, Muhammad MN, Akunna JC (2014) Treatment of metalcontaminated wastewater: a comparison of low-cost biosorbents. J Environ Manag 146:517-523

Abdić Š, Memić M, Šabanović E, Sulejmanović J,·Begić S (2018) Adsorptive removal of eight heavy metals from aqueous solution by unmodified and modified agricultural waste: tangerine peel. Int J Environ Sci Technol 15:2511-2518

Ali H, Khan E, Sajad MA (2013) Phytoremediation of heavy metalsconcepts and applications. Chemosphere 91:869-881

Areco MM, Hanela S, Duran J, Dos Santos AM (2012) Biosorption of $\mathrm{Cu}(\mathrm{II}), \mathrm{Zn}(\mathrm{II}), \mathrm{Cd}(\mathrm{II})$ and $\mathrm{Pb}(\mathrm{II})$ by dead biomasses of green alga Ulva lactuca and the development of a sustainable matrix for adsorption implementation. J Hazard Mater 213-214:123-132

Batty LC (2003) Wetland plants more than just a pretty face? Land Contam Reclam 11(2):173-180

Bettarini I, Colzi I, Coppi A, Falsini S, Echevarria G, Pazzagli L, Selvi F, Gonnelli C (2019) Unravelling soil and plant metal relationships in Albanian nickel hyperaccumulators in the genus Odontarrhena (syn. Alyssum sect. Odontarrhena, Brassicaceae). Plant Soil 440: 135-149

Bhabhatnagar A, Sillanpaa M (2010) Utilization of agro-industrial and municipal waste materials as potential adsorbents for water treatment-a review. Chem Eng J 157:277-296

Bunluesin S, Kruatrachue M, Pokethitiyook P, Upatham S, Lanza GR (2007) Batch and continuous packed column studies of cadmium biosorption by Hydrilla verticillata biomass. J Biosci Bioeng 103: 509-513

Castro L, Bonilla LA, Gonzalez F, Ballester A, Blazquez ML, Muñoz JA (2017) Continuous metal biosorption applied to industrial effluents: a comparative study using an agricultural by-product and a marine alga. Environ Earth Sci 76:491

Chao HP, Chang CC, Nieva A (2014) Biosorption of heavy metals on Citrus maxima peel, passion fruit shell, and sugarcane bagasse in a fixed-bed column. J Ind Eng Chem 20:3408-3414

Colzi I, Lastrucci L, Rangoni M, Coppi A, Gonnelli C (2018) Using Myriophyllum aquaticum (Vell.) Verdc. to remove heavy metals from contaminated water: better dead or alive? J Environ Manag 213:320-328

Coppini E, Palli L, Antal A, Del Bubba M, Miceli E, Fani R, Fibbi D (2019) Design and start-up of a constructed wetland as tertiary treatment for landfill leachates. Water Sci Technol 79:1

Del Bubba M, Anichini B, Bakari Z, Bruzzoniti MC, Camisa R, Caprini C, Checchini L, Fibbi D, El Ghadraoui A, Liguori F, Orlandini S (2020) Physicochemical properties and sorption capacities of sawdust-based biochars and commercial activated carbons towards 
ethoxylated alkylphenols and their phenolic metabolites in effluent wastewater from a textile district. Sci Total Environ 708:135270

Dong Y, Lin H (2017) Competitive adsorption of $\mathrm{Pb}(\mathrm{II})$ and $\mathrm{Zn}$ (II) fromaqueous solution by modified beer lees in a fixedbed column. Process Saf Environ Prot 111:263-269

Fibbi D, Doumett S, Lepri L, Checchini L, Gonnelli C, Coppini E, Del Bubba M (2012) Distribution and mass balance of hexavalent and trivalent chromium in a subsurface, horizontal flow (SF-h) constructed wetland operating as post-treatment of textile wastewater for water reuse. J Hazard Mater 199:209-216

Fu F, Wang Q (2011) Removal of heavy metal ions from wastewaters: a review. J Environ Manag 92:407-418

Gorgoglione A, Torretta V (2018) Sustainable management and successful application of constructed wetlands: a critical review. Sustainability 10(11):3910

Gupta VK, Nayak A, Agarwal S (2015) Bioadsorbents for remediation of heavy metals: current status and their future prospects. Environ Eng Res 20:1-18

Guyo U, Moyo M (2017) Cowpea pod (Vigna unguiculata) biomass as a low-cost biosorbent for removal of $\mathrm{Pb}$ (II) ions from aqueous solution. Environ Monit Assess 189:47

Halaimi FZ, Kellali Y, Couderchet M, Semsari S (2014) Comparison of biosorption and phytoremediation of cadmium and methyl parathion, a case-study with live Lemna gibba and Lemna gibba powder. Ecotoxicol Environ Saf 105:112-120

Hasfalina CM, Maryam RZ, Luqman CA, Rashid M (2012) Adsorption of copper (II) from aqueous medium in fixed-bed column by kenaf fibres. APCBEE Proc 3:255-263

Iqbal M, Saeed A, Edyvean RGJ (2013) Bioremoval of antimony(III) from contaminated water using several plant wastes: optimization of batch and dynamic flow conditions for sorption by green bean husk (Vigna radiata). Chem Eng J 225:192-201

Kankiliç GB, Metin AU, Aluç Y, Bozkayac O (2018) Bioremoval of mercury (II) from aqueous solutions by Phragmites australis: kinetic and equilibrium studies. J Dispers Sci Technol 39:17901799

Kamar FH, Nechifor AC, Nechifor G, Al-Musawi TJ, Mohammed AH (2017) Aqueous phase biosorption of $\mathrm{Pb}$ (II), $\mathrm{Cu}$ (II), and $\mathrm{Cd}$ (II) onto cabbage leaves powder. Int J Chem React Eng 20:150-178

Kariuki Z, Kiptoo J, Onyancha D (2017) Biosorption studies of lead and copper using rogers mushroom biomass 'Lepiota hystrix'. S Afr J Chem Eng 23:62-70

Karunasagar D, Balarama Krishna MV, Rao SV, Arunachalam J (2005) Removal and preconcentration of inorganic and methyl mercury from aqueous media using a sorbent prepared from the plant Coriandrum sativum. J Hazard Mater 118:133-139

Keskinkan O, Goksu MZL, Basibuyuk M, Forster CF (2004) Heavy metal adsorption properties of a submerged aquatic plant (Ceratophyllum demersum). Bioresour Technol 92:197-200

Lagiopoulos I, Binteris A, Mpouras S, Panagiotakis I, Chrysochoou M, Dermatas D (2017) Potential biosorbents for treatment of chromium(VI)-contaminated water discharged into Asopos River. Int J Environ Sci Technol 14:1481-1488

Lee B, Scholz M (2007) What is the role of Phragmites australis in experimental constructed wetland filters treating Urban Runoff? Ecol Eng 29:87-95

Legislative Decree 152/06. Norme in materia ambientale Gazzetta Ufficiale n. 88 del 14 aprile 2006, Supplemento Ordinario n. 96

Marchand L, Mench M, Jacob DL, Otte ML (2010) Metal and metalloid removal in constructed wetlands, with emphasis on the importance of plants and standardized measurements: a review. Environ Pollut 158:3447-3461

Martín-Lara MA, Blázquez G, Calero M, Almendros AI, Ronda A (2016) Binary biosorption of copper and lead onto pine cone shell in batch reactors and in fixed bed columns. Int J Miner Process 148:72-82
Masi F, Rizzo A, Regelsberger M (2018) The role of constructed wetlands in a new circular economy, resource oriented, and ecosystem services paradigm. J Environ Manag 216:275-284

Mitsch WJ (2012) What is ecological engineering? Ecol Eng 45:5-12

Módenes AN, de Oliveira AP, Espinoza-Quiñones FR, Trigueros DEG, Kroumov AD, Bergamasco R (2017) Study of the involved sorption mechanisms of $\mathrm{Cr}(\mathrm{VI})$ and $\mathrm{Cr}(\mathrm{III})$ species onto dried Salvinia auriculata biomass. Chemosphere 172:373-383

Muhamad H, Doan H, Lohi A (2010) Batch and continuous fixed-bed column biosorption of $\mathrm{Cd}^{2+}$ and $\mathrm{Cu}^{2+}$. Chem Eng J 158:369-377

Newete SW, Byrne MJ (2016) The capacity of aquatic macrophytes for phytoremediation and their disposal with specific reference to water hyacinth. Environ Sci Pollut Res 23:10630-10643

Pérez Marín AB, Aguilar MI, Meseguer VF, Ortuño JF, Sáez J, Lloréns M (2009) Biosorption of chromium (III) by orange (Citrus cinensis) waste: Batch and continuous studies. Chem Eng J 155: 199-206

Petrovic M, Sostaric T, Stojanovic M, Petrovic J, Mihajlovic M, Cosovic A, Stankovic S (2017) Mechanism of adsorption of $\mathrm{Cu}^{2+}$ and $\mathrm{Zn}^{2+}$ on the corn silk (Zea mays L.). Ecol Eng 99:83-90

Rahman Z, Singh VP (2019) The relative impact of toxic heavy metals (THMs) (arsenic (As), cadmium (Cd), chromium (Cr)(VI), mercury $(\mathrm{Hg})$, and lead $(\mathrm{Pb}))$ on the total environment: an overview. Environ Monit Assess 191:419

Rai PK (2009) Heavy metal phytoremediation from aquatic ecosystems with special reference to macrophytes. Crit Rev Environ Sci Technol 39:697-753

Rodrigues ACD, do Amaral Sobrinho NMB, dos Santos FB, dos Santos AM, Pereira ACC, Lima ESA (2017) Biosorption of toxic metals by water lettuce (Pistia stratiotes) biomass. Water Air Soil Pollut 228: 156

Sacco C, Pizzo AM, Tiscione E, Burrini D, Messeri L, Lepri L, Del Bubba M (2006) Alkylphenol polyethoxylate removal in a pilotscale reed bed and phenotypic characterization of the aerobic heterotrophic community. Water Environ Res 78:754-763

Saha GC, U1 Hoque MI, Miah MAM, Holze R, Chowdhury DA, Khandaker S, Chowdhury S (2017) Biosorptive removal of lead from aqueous solutions onto Taro (Colocasia esculenta (L.) Schott) as a low cost bioadsorbent: characterization, equilibria, kinetics and biosorption-mechanism studies. J Environ Chem Eng 5: 2151-2162

Sao K, Pandey M, Pandey PK, Khan F (2017) Highly efficient biosorptive removal of lead from industrial effluent. Environ Sci Pollut Res 24:18410-18420

Schwarzenbach RP, Escher BI, Fenner K, Hofstetter TB, Johnson CA, Von Gunten U, Wehrli B (2006) The challenge of micropollutants in aquatic systems. Science 313:1072-1077

Sharma S, Singh B, Manchanda VK (2014) Phytoremediation: role of terrestrial plants and aquatic macrophytes in the remediation of radionuclides and heavy metal contaminated soil and water. Environ Sci Pollut Res 22:946-962

Southichak B, Nakano K, Nomura M, Chiba N, Nishimura O (2006) Phragmites australis: a novel biosorbent for the removal of heavy metals from aqueous solution. Water Res 40:2295-2302

Srivastava S, Agrawal SB, Mondal MK (2015) A review on progress of heavy metal removal using adsorbents of microbial and plant origin. Environ Sci Pollut Res 22:15386-15415

Stanovych A, Balloy M, Olszewski TK, Petit E, Grison C (2019) Depollution of mining effluents: innovative mobilization of plant resources. Environ Sci Pollut Res 26:19327-19334

Talebian A, Keshtkar AR, Moosavian MA (2016) Continuous biosorption of U (VI) and Fe (II) using Cystoseira indica biomass packed bed column: breakthrough curves studies in single, binary and multi-component systems. Korean J Chem Eng 33:2205-2214

Tariq M, Farooq U, Athar M, Salman M, Tariq M (2019) Biosorption of $\mathrm{Cu}$ (II) from aqueous solution onto immobilized Ficus religiosa 
branch powder in a fixed bed column: vreakthrough curves and mathematical modeling. Korean J Chem Eng 36:48-55

Truu M, Juhanson J, Truu J (2009) Microbial biomass, activity and community composition in constructed wetlands. Sci Total Environ 407: 3958-3971

Vijayaraghavan K, Jegan J, Palanivelu K, Velan M (2005) Biosorption of copper, cobalt and nickel by marine green alga Ulva reticulata in a packed column. Chemosphere 60:419-426

Vijayaraghavan K, Yun YS (2008) Bacterial biosorbents and biosorption. Biotechnol Adv 26:266-291

Vinodhini V, Das N (2010) Packed bed column studies on Cr (VI) removal from tannery wastewater by neem sawdust. Desalination 264: $9-14$
Yi Z, Yao J, Zhu M, Chen H, Wang F, Liu X (2017) Biosorption characteristics of Ceratophyllum demersum biomass for removal of uranium(VI) from an aqueous solution. J Radioanal Nucl Chem 313:9-27

Zhang D, Wang C, Bao Q, Zheng J, Deng D, Duan Y, Shen L (2018) The physicochemical characterization, equilibrium, and kinetics of heavy metal ions adsorption from aqueous solution by arrowhead plant (Sagittaria trifolia L.) stalk. J Food Biochem 42:12448

Publisher's note Springer Nature remains neutral with regard to jurisdictional claims in published maps and institutional affiliations. 